\title{
Experimental research on preparation of high strength concrete with rice husk ash instead of silica fume
}

\author{
Yang Ming ${ }^{1,2,3,4}$, Pengliang Sun ${ }^{5}$, Ping Chen ${ }^{1,2,3,4,{ }^{*}}$, Yuanhao Wang ${ }^{1,2,3,4,{ }^{*}}$, Ling $\mathrm{Li}^{1,2,3,4}$, Xuandong Chen ${ }^{1,2,3,4}$, Guoxing \\ $\operatorname{Gan}^{1,2,3,4}$ \\ ${ }^{1}$ Guangxi Key Laboratory of New Energy and Building Energy Saving, Guilin 541004, China; \\ 2. College of Civil and Architecture Engineering, Guilin University of Technology, Guilin 541004, China; \\ ${ }^{3}$ Guangxi Beibu Gulf Engineering Research Center for Green Marine Materials, Guilin 541004, China; \\ 4. Guangxi Engineering and Technology Center for Utilization of Industrial Waste Residue in Building Materials, Guilin 541004, China; \\ ${ }^{5}$ School of Chemical Science and Technology, Yunnan University, Kunming, 650091, China
}

\begin{abstract}
The effect of grinding time on the properties of low-temperature rice husk ash was experimentally studied, and the feasibility of using rice husk ash instead of silica fume to prepare concrete was studied by comparison with silica fume. The results showed that the best grinding time of rice husk ash is 50 minutes, the concrete with similar properties can be prepared by replacing silica fume with super-fine rice husk ash, and the same enhancement effect can be achieved when replacing silica fume with more than $5 \%$, and the performance was consistent.
\end{abstract}

\section{Introduction}

Rice husk ash is the residue of calcined rice husk, which is mainly the inorganic component of rice husk. Because the main elements in rice husk are $\mathrm{C}, \mathrm{H}, \mathrm{O}$ and $\mathrm{Si}$, the main chemical composition of rice husk ash is $\mathrm{SiO}_{2}$, and the content can reach more than $90 \%{ }^{[1]}$ Due to different producing areas and different calcination processes, the chemical composition and mineral composition of rice husk ash will be different. Generally, the $\mathrm{SiO} 2$ of rice husk ash produced by low temperature calcination process is dominated by amorphous form and has high pozzolanic activity. ${ }^{[2]}$

Silica fume is well known as a high-quality concrete admixture, and its excellent filling and activity effect can improve many properties of concrete, however, many demanders are deterred because of its high price and tight supply. In China, the rice husk yield is large, the regional distribution is wide, it has a significant price advantage over silica fume. The experiment on the performance of the existing low temperature rice husk ash and silica fume also to study the preparation of concrete performance, and analyzes the possibility of using rice husk ash as a substitute material for silica fume in the preparation of concrete. To alleviate the shortage of silica fume resources and the resource utilization of rice husk ash with far-reaching significance.

\section{Experimental section}

\subsection{Raw Material}

(1) cement: Yufeng P.O 42.5 grade cement water, 28days compressive strength $48.5 \mathrm{MPa}$; (2) local river sand in Guilin, China, with fineness modulus 2.7; (3) Macadam: local limestone mining, particle size 5 25 mm continuous gradation; (4) ore powder: S95 grade ore powder produced by Liuzhou Iron and Steel Co., Ltd.; (5) Superplasticizer: self-synthesized polycarboxylic acid superplasticizer with a solid content of $20 \%$; (6) Water: tap water; (7) $\mathrm{HCl}$, analysis is pure; (8) $\mathrm{Ca}(\mathrm{OH}) 2$, analytically pure; (9) silica fume: Sichuan Donglan new silica fume; (10) Rice husk ash: low temperature rice husk ash in a power plant, the main chemical composition is shown in Table 1, and the mineral composition is shown in Figure 1.

Table 1 Chemical constituents of rice husk ash (wt \%)

\begin{tabular}{ccccccccccc}
\hline $\mathrm{Wt} \%$ & $\mathrm{SiO}_{2}$ & $\mathrm{Al}_{2} \mathrm{O}_{3}$ & $\mathrm{Fe}_{2} \mathrm{O}_{3}$ & $\mathrm{CaO}$ & $\mathrm{MgO}$ & $\mathrm{K}_{2} \mathrm{O}$ & $\mathrm{Na}_{2} \mathrm{O}$ & $\mathrm{SO}_{3}$ & $\mathrm{P}_{2} \mathrm{O}_{5}$ & $\mathrm{Cl}^{-}$ \\
\hline $\begin{array}{c}\text { Rice } \\
\text { husk } \\
\text { ash }\end{array}$ & 90.13 & 0.78 & 0.61 & 2.67 & 0.49 & 2.41 & 0.06 & 0.09 & 0.54 & 0.38 \\
\hline
\end{tabular}

\footnotetext{
* Correspondence: chenping8383@188.com (P. Chen); gxwangyuanhao@gmail.com (Y. Wang)
} 


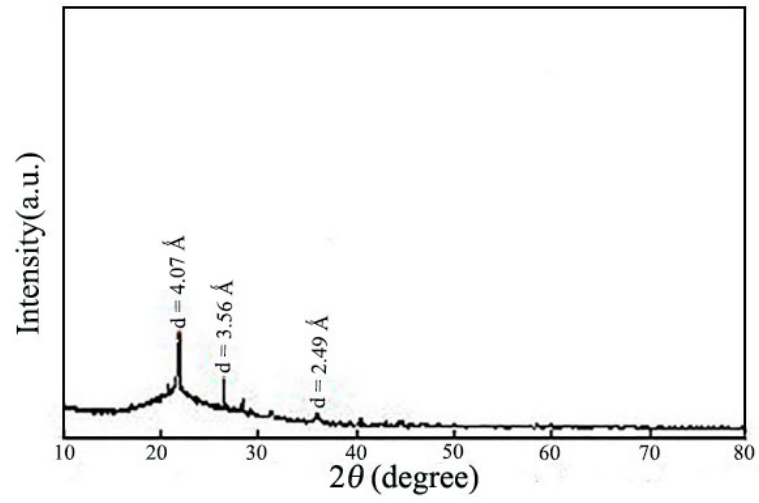

Figure. 1 XRD map of rice husk ash

The analysis shows that the main chemical composition of the rice husk ash is $\mathrm{SiO} 2$, with high content of $\mathrm{CaO}, \mathrm{K} 2 \mathrm{O}$ and so on. The main form of the XRD pattern is a dispersion diffraction peak centered on $\mathrm{d}=4.07 \AA$ and a small amount of quartz characteristic peak exists, indicating that most of the $\mathrm{SiO} 2$ in the rice husk ash is amorphous, only a small part of the rice husk ash has crystal transformation, which is closely related to the calcination temperature of the rice husk ash. Figure 2 is a picture of ultra-fine ground rice husk ash take by JSM-5610LV scanning electron microscope. It can be seen that the particle size of rice husk ash after ultra-fine grinding is mainly below $10 \mu \mathrm{m}$, and the shape of the particles is irregular, the smaller particles are adsorbed and agglomerated easily between larger particles.

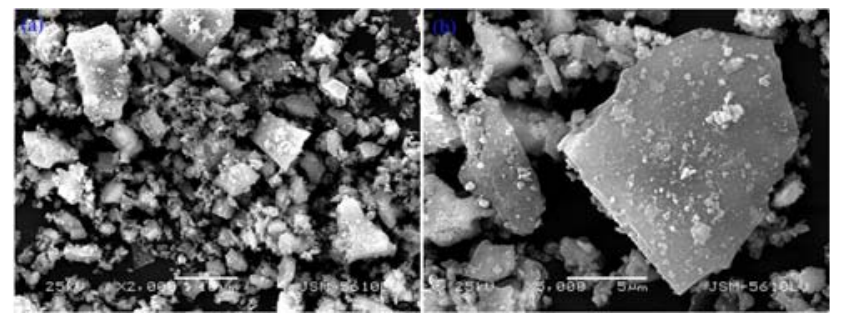

Figure. 2 SEM pictures of ground rice husk ash under different magnification, (a) Magnify 2000 times, (b) Magnify 5000 times.

Table 2 effect of different grinding time on ash fineness of rice husk

\begin{tabular}{lllllll}
\hline Grinding time $/ \mathrm{min}$ & 0 & 20 & 30 & 40 & 50 & 60 \\
\hline $\mathrm{D} 50 / \mu \mathrm{m}$ & 78.23 & 35.31 & 12.69 & 4.95 & 4.08 & 4.01 \\
$45 \mu \mathrm{m}$ Sieve surplus $/ \%$ & 85.3 & 26.7 & 16.0 & 6.2 & 5.3 & 5.2 \\
\hline
\end{tabular}

It can be seen from Table 2 that as the milling time increases, the husk ash gradually becomes finer. The husk ash fineness increases significantly at the initial stage of milling, but more than $50 \mathrm{~min}$, the increase of fineness decreases. The sieve residue of 20 min rice husk ash $45 \mu \mathrm{m}$ is decreased by $58.6 \%$, by contrast, the grinding time increase from $50 \mathrm{~min}$ to $60 \mathrm{~min}$, the rice husk ash $45 \mu \mathrm{m}$ sieve residue decrease only by $0.1 \%$, and the grinding time increase from $40 \mathrm{~min}$ to $50 \mathrm{~min}$, the rice husk ash $45 \mu \mathrm{m}$ sieve residue decrease by $0.9 \%$. The laser particle size D50 test results also show the same rule, which shows that the fineness of rice husk ash powder is difficult to increase any more after a certain period of time. From the experimental results, it can be

\subsection{Experiment method}

(1) testing the mechanical properties of mortar with reference to GB/T17671-1999; (2) testing the properties of concrete mixtures with reference to GB/T50080-2016; (3) testing the mechanical properties of concrete at different ages with reference to GB/T50081-2016, and (4) testing the durability of concrete with reference to GB/T50082-2009.

\section{Results and analysis}

\subsection{Preparation of Superfine Rice husk Ash}

The fineness of mineral admixture is very important for their activity. Usually, physical activation must be carried out by mechanical grinding in practical applications, and it must get the proper grade of fine ash before to meet the requirements of concrete admixture, then, the activity of admixture can be brought into full play. There are many large particles in the original rice husk ash, which can not meet the requirements of the standard for the particle size of mineral admixtures. Through the grinding processing, the admixtures not only powder fine but also improve the activity and water demand performance of the mixture. Therefore, it is necessary to study the effect of grinding time on the fineness, water demand and activity of mineral admixtures.

\subsubsection{Effect of grinding time on fineness}

The rice husk ash was ground by laboratory vibration mill, the fineness sieve residual test was carried out on the samples with different grinding time, and the particle size distribution was tested by Malvern laser particle size analyzer. D50 and $45 \mu \mathrm{m}$ sieve residue were mainly used to evaluate the fineness of rice husk ash powder. The relation between grinding time and fineness is shown in Table 2 . seen that the fineness of the rice hull ash is difficult to increase after the grinding time exceeds $40 \mathrm{~min}$, and the further extending the grinding time is more reflected in the large increase of power consumption.

\subsubsection{Effect of grinding time on activity.}

The mineral admixture must reach a certain fineness to give full play to its activity [3]. Adopt with different fineness of rice husk ash with $0 \mathrm{~min}, 20 \mathrm{~min}, 30 \mathrm{~min}, 40$ min, 50min, 60min were used in the mortar test, and $30 \%$ of the cement was tested according to the standard method. The strength test results of each age are shown in Table 3 . 
Table 3 Test results of rice husk mortar with different grinding time

\begin{tabular}{llllllll}
\hline \multirow{2}{*}{$\begin{array}{l}\text { Grinding time } \\
\text { /min }\end{array}$} & \multicolumn{6}{l}{ Flexural strength $/ \mathrm{MPa}$} & \multicolumn{3}{c}{$\begin{array}{l}\text { Compressive } \\
\text { /MPa }\end{array}$} & strength & \multirow{2}{*}{ 28d Activity index } \\
\cline { 2 - 6 } & $3 \mathrm{~d}$ & $7 \mathrm{~d}$ & $28 \mathrm{~d}$ & $3 \mathrm{~d}$ & $7 \mathrm{~d}$ & $28 \mathrm{~d}$ & \\
\hline Reference & 6.3 & 8.2 & 9.5 & 25.7 & 36.7 & 48.5 & $100 \%$ \\
sample & & & & & & & \\
0 & 4.5 & 5.4 & 6.9 & 16.3 & 22.3 & 28.9 & $59.6 \%$ \\
20 & 5.1 & 6.3 & 8.5 & 19.3 & 27.3 & 39.5 & $81.4 \%$ \\
30 & 5.3 & 6.4 & 8.8 & 20.1 & 28.1 & 42.6 & $87.8 \%$ \\
40 & 5.2 & 6.7 & 8.9 & 21.4 & 29.4 & 45.3 & $93.4 \%$ \\
50 & 5.6 & 6.9 & 9.0 & 22.2 & 30.4 & 46.0 & $94.8 \%$ \\
60 & 5.3 & 6.8 & 9.0 & 22.0 & 31.2 & 46.2 & $95.3 \%$ \\
\hline
\end{tabular}

It can be seen from the data in Table 3:with the increase of grinding time of rice husk ash, the flexural and compressive strength of mortar increases continuously at all ages, It indicatings that sufficient mechanical grinding can increase the activity of rice husk ash. The strength of raw rice husk ash mortar mixed with unground rice husk ash decreased greatly, and the activity index was $81.4 \%$ after grinding $20 \mathrm{~min}$. It can be seen that the grindability of rice husk ash is easy to grind and has better mechanical activation effect. Comparing the activity index of each grinding time, it can find that the relation between grinding time and activity index is not linear, it is very difficult to increase the grain density and activity of rice husk when grinding to a certain time. From the test results it can see that the $28 \mathrm{~d}$ activity index has reached $94.8 \%$ when the grinding time is $50 \mathrm{~min}$, and then the activity of rice husk ash has been fully physically activated.

\subsubsection{Effect of grinding time on water demand.}

As a mineral admixture, rice husk ash is easy to increase water demand because of its porosity and porosity, which is disadvantageous to its application in high performance concrete, but mechanical grinding usually can destroy its porous internal structure and improve the water demand of rice husk ash. The standard consistency water requirement of cement mixed with $30 \%$ rice husk ash at different grinding time was studied and compared with the pure cement. The test results of standard consistency water requirement and water demand ratio are shown in Table 4.

Table 4 effect of different grinding time on water requirement of rice husk ash

\begin{tabular}{llllllll}
\hline Grinding time $/ \mathrm{min}$ & $\begin{array}{l}\text { Pure } \\
\text { cement }\end{array}$ & 0 & 20 & 30 & 40 & 50 & 60 \\
\hline Water requirement $/ \%$ & 26 & 34 & 30.5 & 29 & 27.5 & 28.5 & 29 \\
Water requirement ratio & 1.0 & 1.31 & 1.17 & 1.12 & 1.06 & 1.10 & 1.12 \\
\hline
\end{tabular}

It can be seen from Table 4 that with the increase of grinding time, the water requirement ratio of rice husk ash decreases first and then increases, and the water requirement of $40 \mathrm{~min}$ grinding is the lowest, this is because the rice husk ash itself formed a special porous structure after calcination, and its larger inner surface area creates its larger water demand. With mechanical grinding, the internal porous structure of rice husk ash is destroyed, thus reducing the water demand of rice husk ash. However, the increase of the specific surface area of the powder can also lead to the increase of water demand. When the grinding reaches a certain fineness, the increase of water demand caused by the increase of the specific surface area of rice husk ash powder plays a leading role, thus the overall water demand increases. By comparing to these test results of fineness and activity comprehensively, for obtaining the rice husk ash powder with better comprehensive properties, the ultra-fine rice husk ash with milled $40 \mathrm{~min}$ is selected to carry out further experiments.

\subsection{Comparative experiment of rice husk ash and silica fume.}

\subsubsection{Comparative experiment on the activity of rice husk ash and silica fume}

The ultra-fine rice husk ash and silica fume both with 40 min of grinding were selected for the comparative activity experiments. First, rice husk ash and silica fume were mixed with $\mathrm{Ca}(\mathrm{OH}) 2$ at a mass ratio of $3: 1$, respectively, and added the same amount of water to make the hydration sample, each group of hydration samples were crushed and ground after curing to the required age under the same conditions, $20 \mathrm{~g}$ of ground rice husk ash hydration samples and silica fume hydration samples were taken respectively, and added $100 \mathrm{~g}$ distilled water and two drops of phenolphthalein solution and stir well. The titration test was carried out with hydrochloric acid solution with the concentration of $1.0 \mathrm{~mol} / \mathrm{L}$. The test results are shown in Table 5. 
Table 5 Titration test of rice husk ash and silica fume hydration samples

\begin{tabular}{lllll}
\hline \multirow{2}{*}{ Sample } & \multicolumn{2}{l}{$\mathrm{HCl}$ consumption $/ \mathrm{mL}$} & $\mathrm{Ca}(\mathrm{OH})_{2}$ Residual amount $/ \mathrm{g}$ \\
\cline { 2 - 5 } & $7 \mathrm{~d}$ & $28 \mathrm{~d}$ & $7 \mathrm{~d}$ & $28 \mathrm{~d}$ \\
\hline Rice husk ash & 45.95 & 37.84 & 1.7 & 1.4 \\
Silica fume & 32.43 & 27.03 & 1.2 & 1.0 \\
\hline
\end{tabular}

As see from the test results, with the extension of the test age, the residual amount of $\mathrm{Ca}(\mathrm{OH}) 2$ in the hydration samples of the two admixtures decreased, it showed that the hydration degree of the admixture increases with the increase of the age. $\mathrm{Ca}(\mathrm{OH}) 2$ residue in the same age rice husk ash hydration samples was higher than that of silica fume, which indicated that the water consumption $\mathrm{Ca}(\mathrm{OH}) 2$ of silica fume was more than that of rice husk ash, The pozzolanic activity of rice husk ash was weaker than that of silica fume.

\subsubsection{Effect of different contents of rice husk ash and silica fume on the properties of mortar.}

In order to further study the performance difference between ultra-fine rice husk ash and silica fume prepared by the experiment, in the experiment, $5 \%-20 \%$ of different amounts of mortar were selected for comparison test, and the test results are shown in Figures 3.
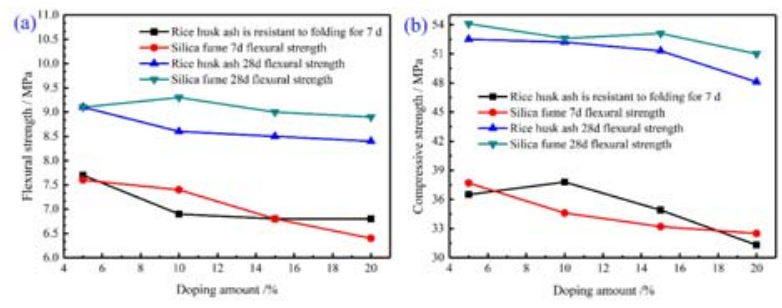

Figure 3 (a) is the comparison of flexural strength at different ages, (b) is the comparison of compressive strength at different ages.

It can be seen from the figure that the compressive strength of mortar can be enhanced by the addition of a small amount of ground rice husk ash and silica fume, but the flexural strength decreased to a certain extent.
With the increase of the content of rice husk ash, the strength of mortar decreased at all ages, and the downward trend was more obvious when the content reached $20 \%$. This is because the pozzolanic mineral admixture it'self can't hydrated, it must be hydrated to produce enough $\mathrm{Ca}(\mathrm{OH}) 2$ to play its activity to form hydration products [4]. Therefore, the excessive substitution of ground rice husk ash for cement will lead to the obvious decrease of mortar strength. With the content of silica fume increases, the flexural strength and compressive strength of mortar decreased in 7 days, just little difference in 28 days. This is because the small particle size of silica fume can be filled between the cement particles, and a small amount of silica fume can improve the overall compactness of the cementitious material and increase the early strength. However, a large amount of silica fume breaks the "tight accumulation" effect, which is disadvantageous to the early strength [5]. From the $28 \mathrm{~d}$ compressive strength, when the content of rice husk ash is $10 \%$, the compressive strength of mortar is the closest to that of silica fume.

\subsubsection{Experiment on preparation of concrete with rice husk ash instead of silica fume.}

It can be found from the rice husk ash mortar test that the activity of low-temperature rice husk ash is higher, especially when the content is $10 \%$, it is close to the strengthening effect of silica fume. In order to verify the possibility of preparing concrete with this rice husk ash instead of silica fume, taking C60 concrete as an example, the comparison test was carried out by grinding rice hull ash and silica fume for $40 \mathrm{~min}$. The design of concrete mix ratio is shown in Table 6 and the test results are shown in Table 7.

Table 6 mix design of concrete test

\begin{tabular}{ccccccccc}
\hline $\begin{array}{c}\text { Serial } \\
\text { numb } \\
\mathrm{er}\end{array}$ & $\begin{array}{c}\text { Ceme } \\
\mathrm{nt} / \mathrm{kg}\end{array}$ & $\begin{array}{c}\text { Rice } \\
\text { husk ash } \\
/ \mathrm{kg}\end{array}$ & $\begin{array}{c}\text { Silica } \\
\text { fume } / \mathrm{kg}\end{array}$ & $\begin{array}{c}\text { Ore } \\
\text { powder } \\
/ \mathrm{kg}\end{array}$ & $\begin{array}{c}\text { Crushe } \\
\mathrm{d} \text { stone } \\
/ \mathrm{kg}\end{array}$ & $\begin{array}{c}\text { River } \\
\text { sand } \\
/ \mathrm{kg}\end{array}$ & $\begin{array}{c}\text { Wat } \\
\mathrm{er} \\
/ \mathrm{kg}\end{array}$ & $\begin{array}{c}\text { Admixtu } \\
\mathrm{re} / \mathrm{kg}\end{array}$ \\
\hline 1 & 300 & 25 & 0 & 175 & 1050 & 760 & 150 & 6.5 \\
2 & 300 & 0 & 25 & 175 & 1050 & 760 & 150 & 6.5 \\
3 & 300 & 50 & 0 & 150 & 1050 & 760 & 150 & 6.5 \\
4 & 300 & 0 & 50 & 150 & 1050 & 760 & 150 & 6.5 \\
5 & 300 & 75 & 0 & 125 & 1050 & 760 & 150 & 6.5 \\
6 & 300 & 0 & 75 & 125 & 1050 & 760 & 150 & 6.5 \\
\hline
\end{tabular}

Table 7 effect of ground rice husk ash and silica fume as admixture on concrete properties

\begin{tabular}{cccccc}
\hline $\begin{array}{c}\text { Serial } \\
\text { numbe } \\
\mathrm{r}\end{array}$ & $\begin{array}{c}\text { slumps } \\
/ \mathrm{mm}\end{array}$ & $\begin{array}{c}\text { Degree of } \\
\text { expansion } \\
/ \mathrm{mm}\end{array}$ & $\begin{array}{c}3 \mathrm{~d} \\
\text { Compression } \\
\text { resistance } \\
/ \mathrm{MPa}\end{array}$ & $\begin{array}{c}7 \mathrm{~d} \\
\text { Compression } \\
\text { resistance } \\
/ \mathrm{MPa}\end{array}$ & $\begin{array}{c}28 \mathrm{~d} \\
\text { Compression } \\
\text { resistance } \\
/ \mathrm{MPa}\end{array}$ \\
\hline 1 & 235 & 630 & 30.8 & 43.1 & 69.1 \\
2 & 230 & 620 & 34.6 & 48.0 & 71.2 \\
3 & 225 & 620 & 33.2 & 50.1 & 71.0
\end{tabular}




\begin{tabular}{llllll}
4 & 210 & 605 & 36.5 & 52.7 & 72.2 \\
5 & 210 & 605 & 34.8 & 53.8 & 72.5 \\
6 & 195 & 580 & 39.5 & 59.4 & 75.1 \\
\hline
\end{tabular}

From the test results, it can be seen that under the condition that the amount of cement and the total amount of cementitious materials are unchanged, the compressive strength of concrete increases with the increase of the amount of rice husk ash and silica fume, which shows that the strengthening effect of rice husk ash and silica fume on concrete is greater than mineral powder.

Compared with same amount of rice husk ash and silica fume, it can be found, the strength of concrete mixed with silica fume at all ages is always higher than that of concrete mixed with rice husk ash, and the strength of concrete mixed with silica fume is higher in the early stage but the later stage is closer. This is because silica fume has finer fineness and higher activity than the ground rice husk ash, and has stronger filling effect and hydration ability in the early stage. However, with the increase of the amount of $\mathrm{Ca}(\mathrm{OH}) 2$ produced by the hydration of cement clinker, rice husk ash is also involved in hydration to produce gel, which gradually catch up with silica fume [6] in the later stage, It indicates that it is feasible to prepare concrete with the same amount of ground rice husk ash instead of silica fume. However, it can't achieve the enhancement effect of silica fume $100 \%$, when the content is $10 \%$, the difference of compressive strength in 28 days between the rice husk ash and silica fume is the smallest, only 1.2 MPA; Compared with tests 2, 3, 4 and 5, it is found that the strength of all ages is close to or even higher than the corresponding concrete strength after replacing silica fume with rice husk ash, the results show that rice husk ash can achieve the same enhancement effect as silica fume when the excess amount of rice husk ash replaces silica fume. In the experiment, when the rice husk ash exceeds $5 \%$, the strength value of each age is basically the same, and the working performance is basically the same, This is because silica fume has a finer specific surface area, with a larger amount of water required for silica fume at the same dosage the working performance is reduced. When the rice husk ash exceeds $5 \%$, this gap is just offset, and the performance is consistent.

\subsubsection{Microscopic analysis}

Figure 4 are 28-day-old SEM photos of C60 concrete prepared with silica fume and ground rice husk ash respectively, in which the doping amount of silica fume is $10 \%$ and the content of ground rice husk ash is $15 \%$. It can be seen from the figure that the internal microstructure of the two kinds of concrete at 28 days of age is very dense, and a large number of amorphous CS-H gel and hydration products can be observed, and there are few flaky calcium hydroxide. This is because both the ultra-fine rice husk ash and silica fume have high pozzolanic activity, which can reduce the content of calcium hydroxide in concrete and improve the microstructure of concrete [7]. The results show that silica fume and ultra-fine rice husk ash can not only fill the dense cementitious material system well, but also give full play to the pozzolanic characteristics and consume a large amount of $\mathrm{Ca}(\mathrm{OH}) 2$ produced by cement hydration, thus making the microstructure of concrete more dense. From the SEM diagram, it can also be found that there are still a small number of unhydrated spherical silica fume particles in the concrete prepared with silica fume, which are tightly wrapped by hydration products in the middle of the hydration products, and the surface has been integrated with the hydration products. No harmful holes and obvious defects were found in the concrete prepared with ultrafine rice husk ash, and the cementitious structure is dense and continuous, so it can be inferred both concretes have good impermeability and corrosion resistance.

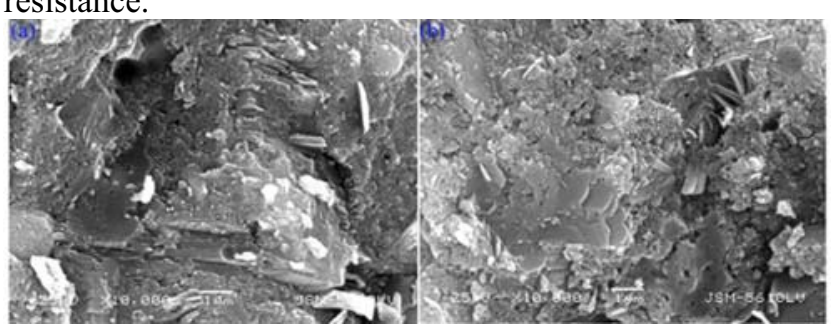

Figure 4 (a) shows the SEM pictures of silica fume at age of 28 days; (b) SEM pictures of 28-aged C60 concrete with ground rice husk ash;

\section{Conclusions}

The main results are as follows:

(i). Mechanical grinding can effectively increase the activity of rice husk ash, but the enhancement effect decreases gradually with the extension of grinding time. When the grinding time exceeds $40 \mathrm{~min}$, the activity and fineness of fine rice husk ash change little, on the contrary, the power consumption will increase greatly.

(ii). With the increase of grinding time, the water requirement ratio of rice husk ash decreases first and then increases, because the rice husk ash itself is porous and the internal surface area is larger, mechanical grinding can destroy its porous structure, thus reducing the water demand of rice husk ash. However, when the grinding reaches a certain fineness, the increase of water demand caused by the increase in the specific surface area of rice husk ash plays a leading role, which is shown as an increase in the overall water demand.

(iii). The pozzolanic activity of the prepared ultrafine rice husk ash is weaker than silica fume, and both the ultra-fine rice husk ash and silica fume can exert a filling effect and the pozzolanic effect can enhance the cementitious system. When the doping amount of ultrafine rice husk ash is $10 \%$, the strength of the mortar is equal to that of the silica mortar.

(iv). It is feasible to use ultra-fine rice husk ash instead of silica fume to prepare low-glue material C60 concrete, in which the equal substitution can not achieve $100 \%$ of the silica fume reinforcement effect, but 
rice husk ash over $5 \%$ can replace silica fume. It has the same enhancement effect as silica fume and the performance is consistent.

\section{Acknowledgement:}

This work was supported by the Guangxi Key Research and Development Program (AB19259008) and GuangXi Key Laboratory of New Energy and Building Energy Saving (Gui Ke Neng : 19-J-21-7, 19-J-21-9, 19-J-21-12 and 19-J-21-31).

\section{Conflicts of Interest:}

The authors declare that they have no conflicts of interest to report regarding the present study.

\section{References}

1. Jauberthie R, Rendell F, Tamba S and Cisse I, Construction and Building Materials. 14, 8 (2000).

2. Habeeb G A and Mahmud H B, Materials research. 13, 2 (2010).

3. Liew $\mathrm{K}$ M, Sojobi A O and Zhang L W, Construction and building materials. 156, (2017).

4. Siddique R, Singh K, Singh M, Corinaldesi, V and Rajor A, Construction and Building materials. 121, (2016).

5. Swaminathen $\mathrm{A} N$ and Ravi $\mathrm{S}$ B, International Journal of Applied Engineering Research. 11, 1 (2016).

6. Basha E A, Hashim R, Mahmud H B and Muntohar A S, Construction and building materials. 19, 6 (2005).

7. Gursel A P, Maryman H and Ostertag C, Journal of Cleaner Production. 112, (2016). 